\title{
ACIDITY LEVELS IN ICE SHEETS FROM
}

\section{RADIO ECHO-SOUNDING}

by

\author{
D. H. M. Millar
}

(Scott Polar Research Institute, University of Cambridge, Cambridge CB2 1ER, England)

\section{ABSTRACT}

It has been suggested (Harmer 1977, Gudmandsen and Overgaard 1978, Mi11ar 1981) that layers of acidic ice, formed after large volcanic eruptions, are a cause of radio echo layering. The power reflection coefficient (PRC) of these reflecting layers may be related to their acid content and thickness. The present paper makes estimates of ice acidity from radio echo-sounding (RES) and compares them with measured values along Greenland ice cores. Dated Antarctic PRC/depth profiles are also presented, and acidity estimates made which give a crude indication of past volcanic activity in the southern hemisphere to $\sim 150 \mathrm{ka} \mathrm{BP}$.

\section{INTRODUCTION}

Two mechanisms have been proposed (Paren and Robin 1975) to account for the stratification echoes observed during radio echo-sounding of the Antarctic ice sheet: changes in ice density and in loss tangent. Consideration of PRC vs depth profiles for Antarctic layering suggests that the density mechanism dominates in the upper 500 to $1000 \mathrm{~m}$ of the ice and the loss tangent mechanism in the deeper ice (Millar 1981). Fluctuations in ice density are observed in ice cores (Gow 1970, Langway 1970), and variations in loss tangent are believed to occur due to changes in the amount of acid impurities present. Hamner (1977) detected acidic ice layers associated with known volcanic eruptions at sites in Greenland, and layers with a high sulphate content, due to volcanic sulphuric acid, have been observed in Antarctica at Dome $C$ and the South Pole (Delmas and Boutron 1980).

In this paper, a method of estimating the acidity of such layers from RES is demonstrated, and results obtained from measurements near Crête, Greenland, compared with the published ice-core acidity profile from that site. Similar Antarctic RES data are presented which, it is suggested, give a broad indication of southern hemisphere volcanic activity to about $150 \mathrm{ka} \mathrm{BP}$.

ESTIMATION AND COMPARISON OF ACID LEVELS IN GREENLAND Paren and Robin (1975) and Paren (1981) show how the reflection coefficient for a single layer of acidic ice may be estimated from the difference between its loss tangent and that of the surrounding ice, $\Delta(\tan \delta)$, and its thickness, $\ell$ :

$$
R=0.25 \sin ^{2}\{2 \pi \ell / \lambda) \cdot\{\Delta(\tan \delta)\}^{2}, \text { for } \ell<\frac{1}{4} \lambda,
$$

where $\lambda$ is the radio wavelength in ice. Loss tangent may be simply related to high frequency conductivity, $\sigma_{\infty}$, by

$$
\tan \delta=\sigma_{\infty} / 2 \pi \mathbf{f}_{\varepsilon_{0}} \varepsilon^{\prime},
$$

where $\varepsilon_{0}$ is the permittivity of free space, $\varepsilon^{\prime}$ the permittivity of the ice, and $f$ the radar carrier frequency.

In the Antarctic, the reflecting horizons responsible for layer echoes are probably groups of closely spaced layers forming a "reflective zone" rather than single layers (Harrison 1973, Hargreaves unpublished). However, near the surface at a high-accumulation site, such as crête, the assumption may be made that reflections usually originate from single layers. This has been justified by a comparison of layer echoes detected with a short pulse (4 ns) radar with those seen at pulse lengths of 60 and $250 \mathrm{~ns}$, and also by the correlation of layer echoes with the positions of single high conductivity layers (Gudmandsen and Overgaard 1978). Ice-core acidity measurements (Hammer 1980) show that layers of ice containing high concentrations of volcanic acids have durations of one to two years, so in this case a reflecting layer thickness equivalent to one year's accumulation $\left(0.285 \mathrm{~m} \mathrm{a}^{-1}\right.$ at Crête) is used, which also allows direct comparison with the annual acidity values measured on the ice core.

Hence, we estimate, from Equations (1) and (2), the change in high frequency conductivity $\left(\Delta \sigma_{\infty}\right)$ between a single reflecting layer $0.285 \mathrm{~m}$ thick (thinning in the upper $400 \mathrm{~m}$ is small and is not allowed for here) and the surrounding ice that will account for the observed layer reflection coefficients. Knowing the high frequency conductivity of "background" polar ice, we may then calculate $\sigma_{\infty}$ (layer). To convert this into an acidity, we now represent acidic polar ice by an HF-doped ice and estimate the equivalent HF concentrations that would be required in order to obtain the same high frequency conductivities for the layer and the background, using the laboratory measurements of Campl in and others (1978) at the appropriate ice temperature $\left(\sim-30^{\circ} \mathrm{C}\right.$ near the surface at Crête). This procedure is necessary because there are no experimental measurements available of high frequency conductivity for polar ice doped with volcanic impurities, and HF. doped laboratory ice is the closest available approximation; from these two "equivalent HF concentrations" we can thus estimate the equivalent elevated HF concentration necessary to account for the reflections. We arrive at an estimate of the ice-sheet acidity by adding this additional concentration to the known 


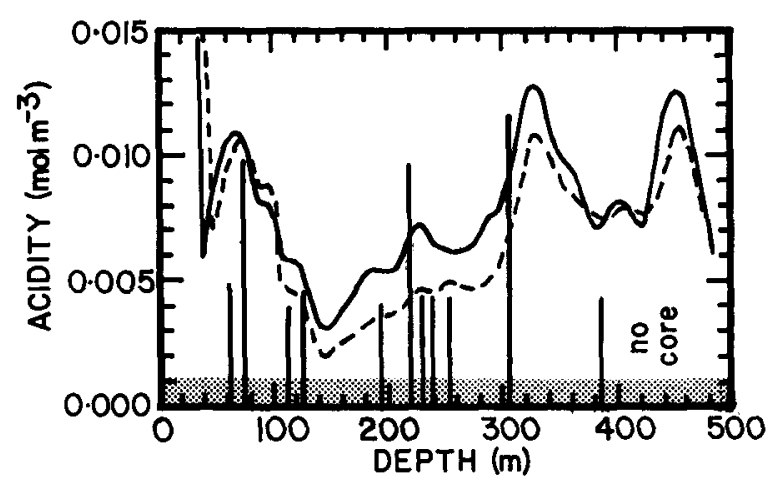

Fig.1. Comparison of mean annual acidities derived from RES at two sites near Crête (solid and dashed lines) and from ice-core measurements on a $404 \mathrm{~m}$ core (Hammer and others 1980). Shaded area represents background acidity of $1.1 \times 10^{-3} \mathrm{~mol} \mathrm{~m}^{-3}$ estimated from ice-core measurements.

background concentration in polar ice,

$(1.1 \pm 0.1) \times 10^{-3} \mathrm{~mol} \mathrm{~m}^{-3}$ (Hammer and others 1980 ).

In Figure 1, we compare these derived acidities from RES data with mean annual $\mathrm{H}^{+}$concentrations measured on the $404 \mathrm{~m}$ core from Crête by a scratch conductivity technique (Hammer and others 1980). The RES data used are single A-scopes recorded during the 1974 season of the Danish-American RES programme. Although variations in PRC, due to fading, are expected between A-scope frames, the similarity of the two frames suggests that this is not pronounced here. The depth ranges of the RES profiles are calculated from the time range by assuming a radio wave propagation velocity of $168 \mathrm{~m} \mu \mathrm{s}^{-1}$ (Johari and Charette 1975 Robin 1975), and, using the density/depth data for Crête in Herron and Langway (1980), making a $10 \mathrm{~m}$ correction for the higher velocities in the firn layer above the shallowest detected radio echo layer (cf Robin and others 1969), and are considered accurate to $\pm 5 \mathrm{~m}$. Reflection coefficients are calculated from received power measurements as described in Robin and others (1969) and el sewhere, using laboratory values of the temperature-dependent absorption coefficient and an estimated temperature profile with a basal temperature of $\sim-10^{\circ} \mathrm{C}$. The RES acidity profiles appear smoothed because of the long pulse length of the radar $(40 \mathrm{~m}$ in ice), but it is clear that each of the three highest acjidity layers measured on the ice core corresponds to a peak on the RES records. The absolute magnitudes of the derived profiles are also very similar to the ice-core values. It should be borne in mind that the background acidity measured at Crête is much lower than that of HF-doped ice with the same conductivity $\left(1.1 \times 10^{-3}\right.$ and $7.2 \times 10^{-3}$ mol $\mathrm{m}^{-3}$, respectively). We do not, therefore, necessarily expect the acidities derived from RES to be equal to the measured acidities, but to be related in some way. The similarity of the profiles indicates, however, that the observed layer echo strengths may be satisfactorily explained by representing the reflecting surfaces by layers of HF-doped ice with an acidity elevation similar to the excess acidities known to occur in the ice due to volcanic acid fallout.

It is interesting to note that one of the first observed internal reflections, near Camp Century in 1964 (Robin and others 1969), was dated at $957 \pm 100$ a $A D$. This is very close to the date of the highest acidity 1 ayer detected in the $404 \mathrm{~m}$ crête core, and correlates with the eruption of Eldgjā, Iceland, in $934 \pm 2$ a AD. Therefore, it seems likely that this layer echo did not arise, as first thought, from a density fluctuation caused by "a few days of warm weather", but from the high acidity layer due to this eruption.
The comparison with measured acidity levels may be extended by comparing the complete RES-derived acidity vs age profile for Crête with the measured acidity record at Camp Century which goes back to $\sim 10 \mathrm{ka}$ BP (no suitable RES power measurements are presently available from Camp Century). However, we cannot assume that reflections from depths greater than a few hundred metres at crête come from isolated thin reflectors. Since the mean spacing of high acidity layers (i.e. those several times the background acidity) in the upper $400 \mathrm{~m}$ is only slightly greater than the pulse length (Fig.1), it is clear that, by about halfway through the ice sheet, we are likely to encounter more than one reflecting surface in the spatial pulse length. This is, in fact, noticeable on $Z$-scope records when changing the pulse length from 250 to $60 \mathrm{~ns}$ ( $i . e$. $\sim 40$ to $10 \mathrm{~m}$ in ice); those which appear as single layers at 250 ns can be resolved into two or three layers at the shorter pulse length at depths of $\sim 500 \mathrm{~m}$ and below (Gudmandsen and Overgaard 1978). Also, the mean spacing between layers does not generally decrease with depth, as would be expected on average for single layers because of the thinning of annual layers with depth. Furthermore, if we estimate acidities on the assumption that the reflectors have a thickness equivalent to one year's accumulation (i.e. thinning with depth), the derived values become unreasonably large at depths $>1000 \mathrm{~m}$. When several reflecting surfaces occur in the space of a pulse length and their separations and thicknesses are not known, an accurate estimate of the total reflection coefficient is not possible. However, Clough (1977) has shown by numerical modelling that, for closely-spaced reflecting layers with randomly varying layer spacing and thickness, the total reflection coefficient is well approximated by that for a single interface with an averaged change in dielectric properties. For a layer of given reflection coefficient, the corresponding change in high frequency conductivity (and hence the derived acidity) is not very dependent on the assumed layer thickness when this is greater than about $0.2 \mathrm{~m}$ at the present radio wavelength of $2.8 \mathrm{~m}$, until interference effects dominate the returned power, and is also very similar to that obtained for a simple interface ( $F i g .2)$. A layer thickness equivalent to one year's accumulation at the surface is therefore assumed here for the entire ice column, and allows continuity with acidity estimates near the surface. The high frequency conductivity of HF-doped ice varies with temperature, and the effect of this may be significant in the deeper (warmer) ice. The effect is, however, small (cf. Figs.3(a) and (b)) because the conductivity of the background ice also changes with temperature, and the difference between the two remains relatively constant.

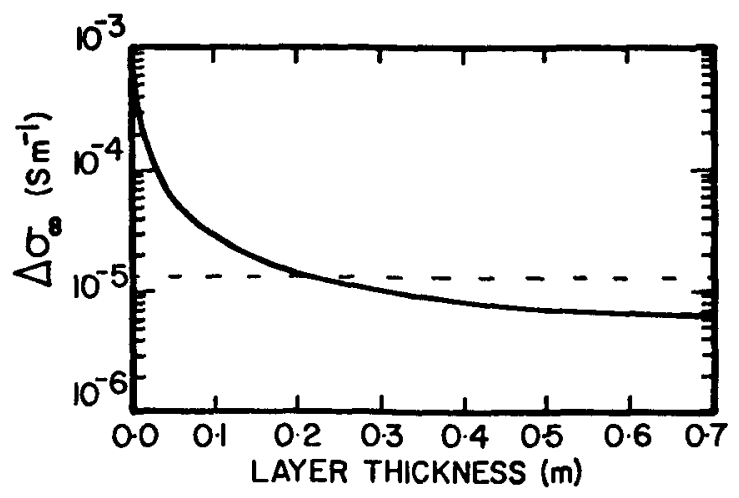

Fig.2. Necessary change in high frequency conductivity $\left(\Delta \sigma_{\infty}\right)$ to produce a reflection coefficient of $-70 \mathrm{~dB}$ for layers of acidic ice of varying thickness up to $0.25 \lambda(0.7 \mathrm{~m})$, and for a simple interface (dashed line). 
DEPTH AT CRÊTE $(\mathrm{km})$

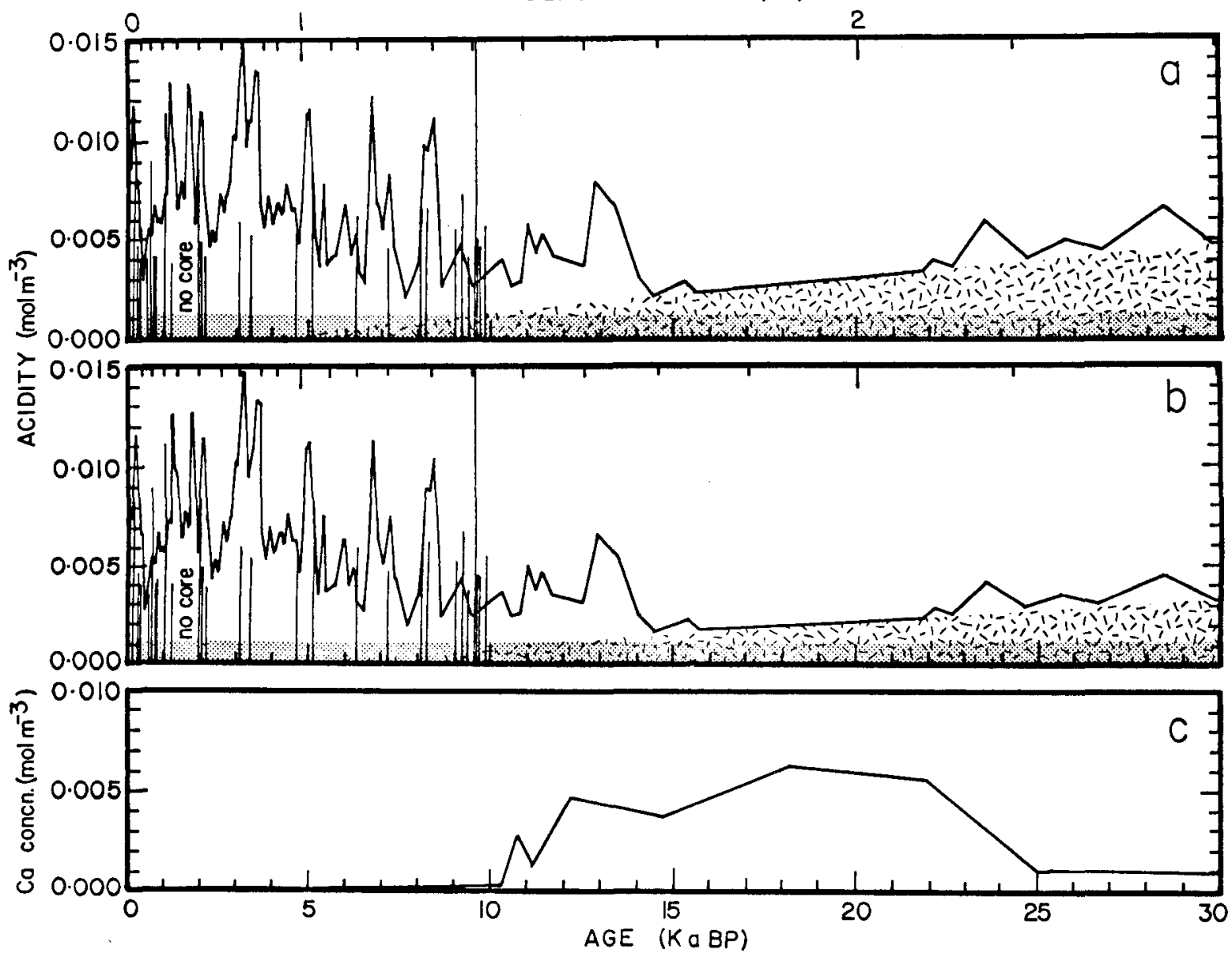

Fig.3. Comparison of mean annual acidities from ice-core measurements at Crête (0 to $1.5 \mathrm{ka} B P$ ) and at Camp Century (>2 ka BP) (vertical bars), with acidities derived from RES near Crête (solid line). Measured layer depths shown by upper scale, dates from model of Dansgaard and Johnsen (1969) $\left(H=2750 \mathrm{~m}, A=0.285 \mathrm{~m} \mathrm{a}^{-1}, \mathrm{~h}=1400 \mathrm{~m}\right)$ on lower scale. Shading represents background acidity as measured on ice cores; speckled region denotes limit imposed by RES system sensitivity. (a) Acidities estimated assuming a constant ice termerature of $-30^{\circ} \mathrm{C}$ and reflector thickness of $0.285 \mathrm{~m}$. (b) Acidities estimated assuming a temperature profile with a basal temperature of $-10^{\circ} \mathrm{C}$ and reflector thickness of $0.285 \mathrm{~m}$. (c) Calcium concentration measured in Camp Century core (Cragin and others 1977); dating from Hammer and others (1978) and comparable with ice-core acidity measurements.

Mean annual acidities measured on the Camp Century core (Hammer and others 1980) are compared with acidities estimated from RES at Crête in Figures $3(a)$ and (b). Layer depths at Crête have been dated using the non-uniform vertical strain rate model of Dansgaard and Johnsen (1969), estimating their parameter $h$ from the data of Reeh and others (1978); measured depths are al so shown in the figure. Most of the strong acidity signals from the Camp Century core are found to correspond to peaks on the RES record, but, below a depth of about $1000 \mathrm{~m}$, the radio echo peaks appear to become displaced by up to $50 \mathrm{~m}$ (approximately one pulse length) from the ice-core acidity peaks. This may be due to a systematic error in dating between the two sites or to a genuine effect caused by a multiple reflector. At $\sim 9$ to $10 \mathrm{ka}$ BP, ka BP, seven high-acidity layers occur within a distance of $\sim 80 \mathrm{~m}$ and do not appear to correlate with a radio echo layer; it is suggested that interference effects may be responsible for this anomaly. Note that there are no ice-core acidity data avallable for 1.5 to $2 \mathrm{ka} \mathrm{BP}$, where the RES data indicate a strong acid layer at about $1.60 \pm 0.15 \mathrm{ka} B P$. The RES record prior to $10 \mathrm{ka}$ BP shows very low acid levels between 14 to $23 \mathrm{ka}$ BP (corresponding to the gap in layering reported by Gudmandsen (1975)I and some poorly resolved low peaks extending to $\sim 30 \mathrm{ka} \mathrm{BP}$, where dielectric absorption limits the technique. Hammer and others (1980) al so report very poorly conducting ice at Camp Century from this period. It seems likely that both these observations may be explained by chemical neutralization of any acids present by calcareous dust, possibly blown onto the ice sheet at the end of the last glaciation from areas of exposed glacial outwash or former shallow water areas, as suggested by Cragin and others (1977). Calcium concentrations of a level which would obliterate or greatly diminish any volcanic signals between about 11 to $25 \mathrm{ka} B P$ have been measured in the Camp Century core (Fig.3(c)). It should be noted that such large sustained calcium levels may have a significant effect on the dielectric properties of the ice at this depth. This may influence estimated reflection coefficients and, hence, acidities in the ice below the high calcium zone, and explain the very low acidities estimated from RES prior to $23 \mathrm{ka} B P$.

In the Antarctic, returns from density fluctuations dominate those from acidic ice layers at depths $<500 \mathrm{~m}$ (Millar 1981). At Crête, this does not seem to be the case, returned power showing no rapid fall- 
off with depth near the surface, and the shallowest layers correlating with high conductivity layers (Gudmandsen and Overgaard 1978). The explanation lies in the fact that the reflection coefficients measured at Crête are typically 10 to $20 \mathrm{~dB}$ greater than for Antarctic layers. This in turn may be associated with the disproportionate concentration of active volcanoes in the northern hemisphere (Porter 1981) which probably causes greater amounts of volcanic acids to be deposited on Greenland than on the Antarctic. Generally higher accumulation rates in Greenland will also favour the acidic ice layer mechanism over the density fluctuations mechanism.

\section{THE ANTARCTIC ACIDITY RECORD}

In central Antarctica, accumulation rates are much lower than in Greenland, and many acidic ice layers are therefore expected to contribute to each layer echo, even at the shallowest depths for which echoes are observed. This is apparent when varying the pulse length and from the uniformity of echo spacings with depth, as mentioned above for the deeper layers at crête. Any estimate of acidities from RES in the Antarctic must therefore be inherently uncertain, and there are also no detailed conductivity measurements along ice cores with which to compare the results. In these circumstances we shall only attempt a crude analysis of the Antarctic RES data.

Since the effect of varying ice temperature has been shown to be small (cf. Figs.3(a) and (b)), a constant ice temperature of $-30^{\circ} \mathrm{C}$ will be assumed. The true thickness and spacing of individual acidic ice layers is not known, and in central east Antarctica it is unlikely that they are properly resolved even with the shortest available pulse length $(60 \mathrm{~ns}$, or $\sim 10 \mathrm{~m}$ in ice). Reflectors are treated as simple interfaces here (Clough 1977). Experimental values for 1 ayer reflection coefficients were obtained from flights of the 1974-75 season of the NSF-SPRI-TUD RES programme. Power measurements were made at $\sim 2 \mathrm{~km}$ interintervals along the track, and PRCs averaged over distances of 25 to $50 \mathrm{~km}$ in order to reduce the effects of fading. The layers were dated using a simple accumulation model near Dome $C$ (Lorius and others 1979) and a flow-line model at Vostok (Budd and Young, personal communication to $G$ de $Q$ Robin): Figure 4 shows examples of the resulting PRC/age profiles, which show only power maxima for clarity and not low power levels between layer echoes as in Figure 3. A schematic acidity profile has been estimated from such measurements (Fig.5), with the simplifying assumptions of constant ice temperature and treating layers as single interfaces. Because only power maxima were considered, this diagram represents

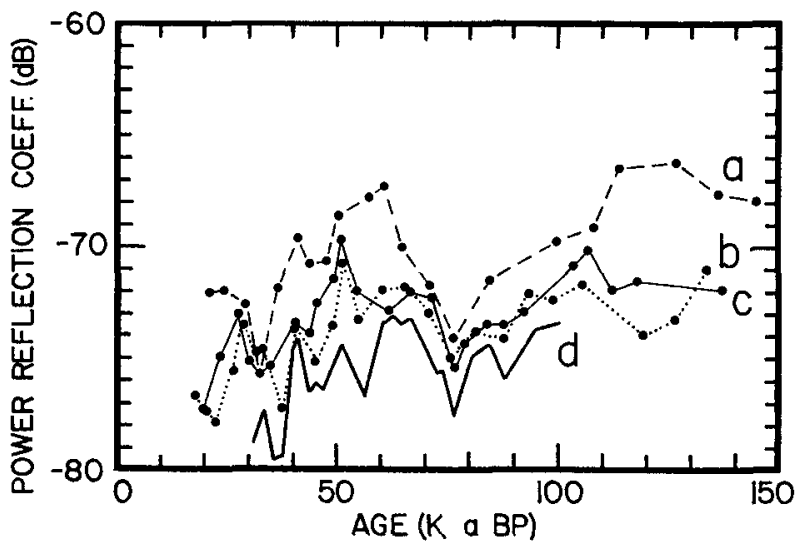

Fig.4. Reflection coefficient vs age profiles from the Antarctic. Measurements at $\sim 2 \mathrm{~km}$ intervals and averaged over 25 to $50 \mathrm{~km}$ of track around site. (a) $\sim 100 \mathrm{~km} \mathrm{NW}$ of Dome $C$, (b) $\sim 100 \mathrm{~km} \mathrm{SE}$ of Dome C, (c) Dome C, (d) Vostok.

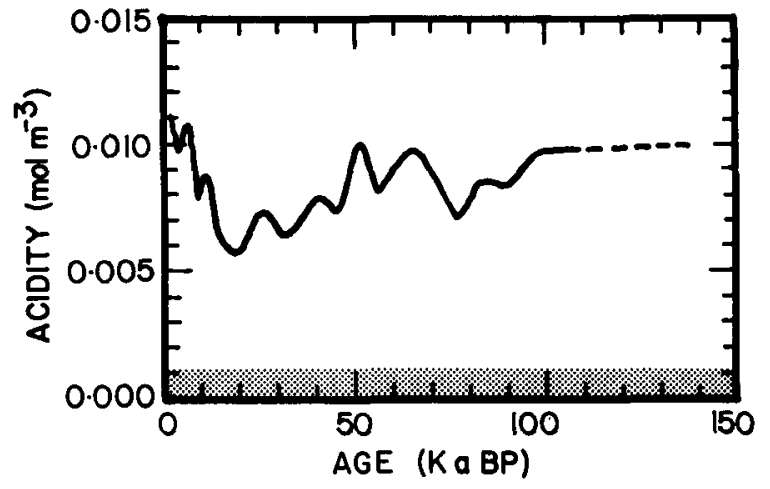

Fig.5. Schematic acidity profile compiled from PRC/age measurements at many Antarctic sites, estimated with the simplifying assumptions of constant ice temperature and that reflectors are single interfaces. Diagram represents the envelope of high acidity values and not the background acidity. Shading represents the assumed background acidity of $1.1 \times 10^{-3} \mathrm{~mol} \mathrm{~m}^{-3}$.

the envelope of the high acidity values and does not not show the background acidity.

It should be stressed that this is necessarily a simple analysis, and that the very thin annual layers may mean that the absolute values of acidity are in error. However, its value lies in identifying periods of particularly low or high acidity that are sustained for long periods, and in averaging ice properties over representative areas rather than at isolated points (with uncertainties due to accumulation variability). It is interesting that a "low" occurs at $\sim 15$ to $25 \mathrm{ka} \mathrm{BP}$, during the most intense part of the last glaciation.

Hammer (1977) found that acidity peaks in Green1 and were mainly due to northern hemfsphere eruptions, and similarly it is expected that Antarctic acidity levels will largely reflect volcanism in South America, the Pacific islands, and Indonesia. The poor temporal resolution of the profile and the few known eruptions during this period make a comparison between the two unsatisfactory.

\section{CONCLUSIONS}

A method for the remote determination of acidity levels in high conductivity layers in polar ice sheets using RES has been described. Although the method relies on representing acidic polar ice by 1 aboratory ice doped with $\mathrm{HF}$, the resulting elevated $\mathrm{H}^{+}$concentrations are in excellent agreement with icecore measurements. Despite the poor resolution compared to ice-core measurements, the technique is nevertheless useful because of its ability to give a representative profile for wide areas rather than at single points, and the much greater ease of penetrating into deeper ice.

\section{ACKNOWLEDGEMENTS}

I am grateful for the helpful supervision of Dr $G$ de $Q$ Robin, and should also like to thank Dr C U Hammer for useful discussions and encouragement, and Dr S Overgaard for kindly providing data from the Danish-American RES programme in Greenland. Financial support in the form of a Research Studentship from the Natural Environment Research Council was much appreciated.

\section{REFERENCES}

Camplin G C, Glen J W, Paren J G 1978 Theoretical models for interpreting the dielectric behaviour of HF-doped ice. Journal of Glaciology 21(85): 123-141

Clough J W 1977 Radio-echo sounding: reflections from internal layers in ice sheets. Journal of Glaciology 18(78): 3-14 
Cragin $J \mathrm{H}$, Herron $M M$, Langway $C \mathrm{C} \mathrm{Jr}$, Klouda $G$ 1977 Interhemispheric comparison of changes in the composition of atmospheric precipitation during the last Cenozoic era. In Dunbar, Maxwell J (ed) Polar oceans. Proceedings of the polar oceans conference, Montreal 1974. Calgary, Arctic Institute of North America: 617-631

Dansgaard W, Johnsen S J 1969 A flow model and a time scale for the ice core from Camp Century, Greenland. Journal of Glaciology 8(53): 215-223

Delmas R, Boutron C 1980 Are the past variations of the stratospheric sulfate burden recorded in central Antarctic snow and ice layers? Journal of Geophysical Research 85(C10): 5645-5649

Gow A J 1970 Preliminary results of studies of ice cores from the $2164 \mathrm{~m}$ deep drill hole, Byrd Station, Antarctica. International Association of Scientific Hydrology Publication 86 (ISAGE): 7890

Gudmandsen P 1975 Layer echoes in polar ice sheets. Journal of Glaciology 15(73): 95-101

Gudmandsen $P$, Overgaard $S 1978$ Establishment of time horizons in polar ice sheets by means of radio echo sounding. Technical University of Denmark, Lyngby. Electromagnetics Institute, Paper P312

Hammer C U 1977 Past volcanism revealed by Greenland ice sheet impurities. Nature 270(5637): 482-486

Hammer C U 1980 Acidity of polar ice cores in relation to absolute dating, past volcanism, and radio echoes. Joumal of Glaciology 25(93): 359-372

Hammer C U, Clausen H B, Dansgaard W 1980 Greenland ice sheet evidence of post-glacial volcanism and its climatic impact. Nature 288(5788): 230235

Hargreaves N D Unpublished. Radio-echo studies of the dielectric properties of ice sheets. (PhD thesis, University of Cambridge, 1977)

Harrison C H 1973 Radio echo sounding of horizontal layers in ice. Joumal of Glaciology 12(66): 383397

Herron M M, Langway C C Jr 1980 Firn densification: an empirical model. Journal of Glaciozogy 25 (93): 373-385

Johari G P, Charette P A 1975 The permittivity and attenuation in polycrystalline and single-crystal ice Ih at 35 and $60 \mathrm{MHz}$. Journal of Glaciology 14(71): 293-303

Langway C C Jr 1970 Stratigraphic analysis of a deep ice core from Greenland. Geological Society of America. Special Paper 125

Lorius C, Merlivat L, Jouzel J, Pourchet M 1979 A 30,000-yr isotope climatic record from Antarctic ice. Nature 280(5724): 644-648

Millar D H M 1981 Radio-echo Jayering in polar ice sheets and past volcanic activity. Nature 292 (5822): 441-443

Paren J G 1981 Reflection coefficient at a dielectric interface. Joumal of Glaciology 27(95): 203-204

Paren J G, Robin G de Q 1975 Internal reflections in polar ice sheets. Journal of Glaciology 14(71):

Porter S C 1981 Recent glacier variations and volcanic eruptions. Nature 291(5811): 139-142 Reeh N, Clausen H B, Dansgaard W, Gundestrup N, Hammer C U, Johnsen S J 1978 Secular trends of accumulation rates at three Greenland stations. Journal of Glaciology 20(82): 27-30

Robin $G$ de $Q 1975$ Velocity of radio waves in ice by means of a bore-hole interferometric technique. Journal of Glaciology 15(73): 151-159

Robin $G$ de $Q$, Evans S, Bailey J T 1969 Interpretation of radio echo sounding in polar ice sheets. Phizosophical Transactions of the Royal Society of London Ser A 265(1166): 437-505 